Check for updates

Cite this: Phys. Chem. Chem. Phys., 2017, 19, 23585

Received 22nd March 2017, Accepted 2nd May 2017

DOI: $10.1039 / c 7 c p 01838 j$

rsc.li/pccp

\title{
Near-infrared photochemistry at interfaces based on upconverting nanoparticles
}

\author{
Si Wu (iD * and Hans-Jürgen Butt
}

\begin{abstract}
Near-infrared (NIR) light is better suited than ultraviolet (UV) light for biomedical applications because it penetrates deeper into tissue and causes less photodamage to biological systems. The use of NIR light to control biointerfaces has attracted increasing interest. Here, we review NIR photoreactions at interfaces based on upconverting nanoparticles (UCNPS). UCNPs can convert NIR light to UV or visible light, which can then induce photoreactions of photosensitive compounds. This process is referred to as UCNP-assisted photochemistry. Recently, we and others demonstrated UCNP-assisted photochemistry at interfaces to control interfacial properties of nano-carriers, implants, emulsions, and cells. We introduce the fundamentals of UCNP-assisted photochemistry at interfaces, highlight its potential applications, and discuss remaining challenges.
\end{abstract}

\section{Introduction}

Interfacial properties of materials are important for diverse applications in our daily lives, fundamental research, and industry. Light provides a non-contact way to control interfacial properties with high spatiotemporal resolution. The development of photosensitive interfaces has attracted a lot of attention (Fig. 1). ${ }^{1-8}$ Grafting photosensitive compounds on a substrate can prepare photosensitive surfaces (Fig. 1a). Photoreactions such as photoisomerization, photopolymerization, photolysis, and

Max Planck Institute for Polymer Research, Ackermannweg 10, 55128 Mainz, Germany.E-mail: wusi@mpip-mainz.mpg.de

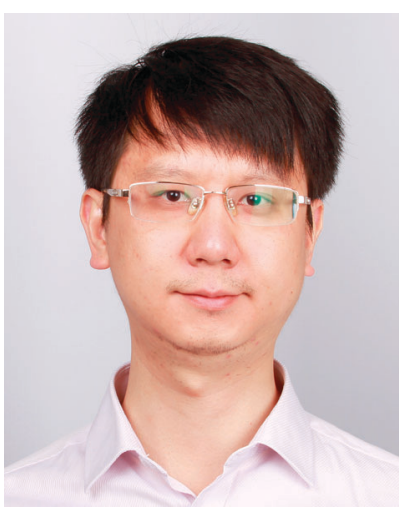

Si Wu
Si Wu is a group leader at the Max Planck Institute for Polymer Research (MPIP), Mainz, Germany. He obtained the bachelor's degree in polymer science in 2005 at the University of Science and Technology of China (USTC), Hefei, China. He was supported by the joint doctoral promotion program working on photoresponsive polymers at MPIP and USTC. After he received his $P h D$ in 2010, he worked as a postdoctoral researcher at MPIP. He was promoted to a group leader at MPIP in 2012. He is now heading an experimental group focusing on synthesis of photoresponsive polymers and photoresponsive nanomaterials. photo-coupling on a substrate can control surface properties and functions. ${ }^{1,2,4-10}$ These surface photoreactions have been used for controlling wettability, ${ }^{2,4,6,11,12}$ preparing coatings and patterns, ${ }^{7,13-15}$ controlling motions of objectives on a surface, ${ }^{2,4}$ regulating adhesion, ${ }^{16,17}$ and switching electromagnetic devices. ${ }^{18,19}$ A topic under intense investigation is photosensitive surfaces of nanoparticles (NPs) (Fig. 1b). NPs have large surface areas; their stability, properties and functions are strongly influenced by their surface properties. Inducing photoreactions at NP surfaces is an elegant way to manipulate NPs. ${ }^{20-23}$ A topic related to photoreactions at surfaces is photoreactions at other interfaces (Fig. 1c). Photosensitive surfactants, amphiphiles, lipids, and colloids are usually used for interfacial

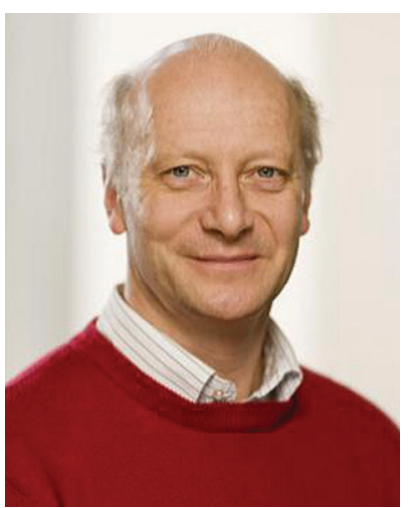

Hans-Jürgen Butt
Hans-Jürgen Butt is a director at the Max Planck Institute for Polymer Research (MPIP), Mainz. He studied physics in Hamburg and Göttingen. He defended his PhD thesis in 1989 at the Max Planck Institute for Biophysics (MPIBP). After one-year postdoc experience at the University of California, he moved back to MPIBP and habilitated in 1995. In 1996, he became a C3 (Associate) professor at the Johannes Gutenberg-University in Mainz. In 2000, he became a C4 (Full) professor at the University of Siegen. In 2002, he joined MPIP as a director working on surfaces and interfaces of soft matter. 


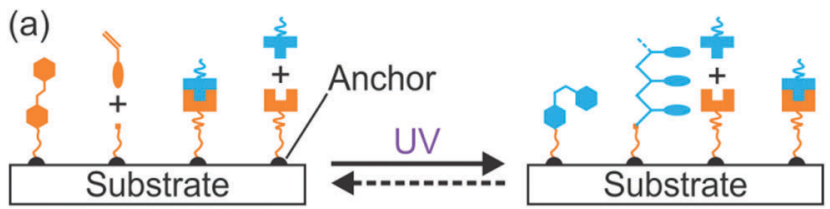

(b)

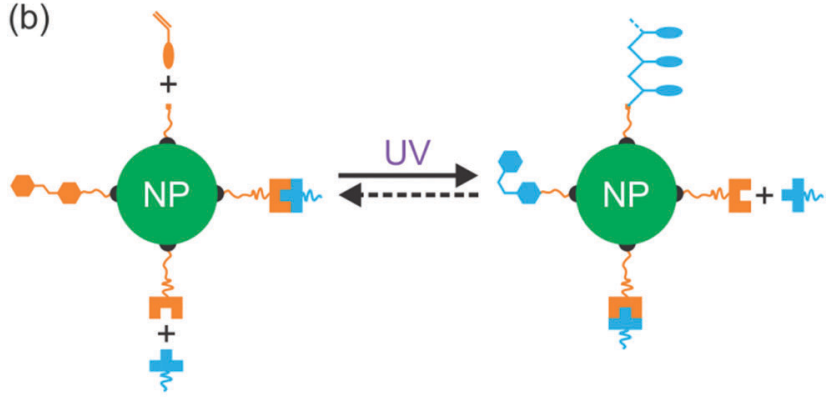

(c)

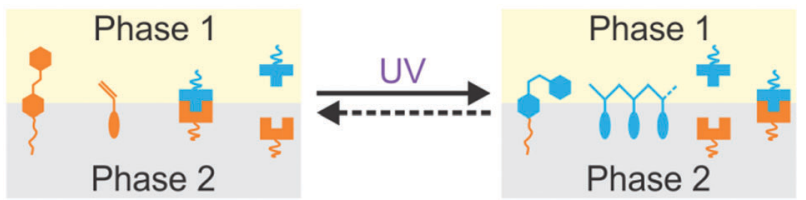

Fig. 1 Photoreactions induced by UV light at the surface of a substrate (a), the surface of a nanoparticle (b), and an interface (c).

photoreactions. ${ }^{24-26}$ Interfacial photoreactions can modulate the interfacial tension, ${ }^{25}$ drive the movement of objectives at an interface, ${ }^{25,27}$ control transportation across membranes, ${ }^{28,29}$ change morphologies of membranes, ${ }^{30,31}$ and control Marangoni and coffee-ring effects. ${ }^{32,33}$

Photoreactions at interfaces have been used for biomedical applications. For example, UV-light-controlled protein adsorption and cell adhesion have been demonstrated. ${ }^{34-38}$ Fan et al. improved targeting specificity of nano-carriers by uncaging targeting groups using UV light. ${ }^{21}$ In the above-mentioned examples, UV light was used to induce photoreactions at interfaces. However, UV light is problematic for some biomedical applications. In contrast, near-infrared (NIR) light in the "therapeutic window" is better suited than UV light for these applications because NIR light can penetrate deeper into tissue and causes less photodamage to cells (Fig. 2a). ${ }^{39-42}$ Therefore, NIR light is superior to UV light for controlling interfacial properties of implants in the body or regulate interfacial functions of nano-carriers for improved therapeutic efficiency (Fig. 2b).

Conventional NIR photoreactions are induced by simultaneous two-photon absorption. ${ }^{43}$ Two NIR photons (e.g., $\lambda=800 \mathrm{~nm}$ ) need to be simultaneously absorbed by a UV-sensitive compound (e.g., absorption at $400 \mathrm{~nm}$ ). NIR photoreactions at interfaces based on two-photon absorption have been extensively studied, e.g. for potential applications in lithography and controlled drug release. ${ }^{44-46}$ However, two-photon absorption is not efficient even when high-intensity (typical pulse intensity: $>10^{6} \mathrm{~W} \mathrm{~cm}^{-2}$ ) 44,45 femtosecond lasers are employed. Additionally, two-photon absorption only occurs at the laser focus. As the femtosecond laser will defocus while passing through tissue, the two-photon absorption approach is impractical to trigger deep-tissue photoreactions. (a)

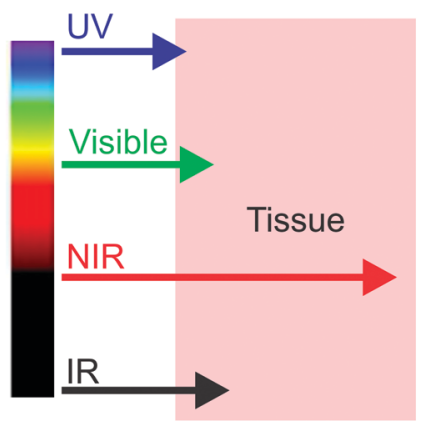

(b)

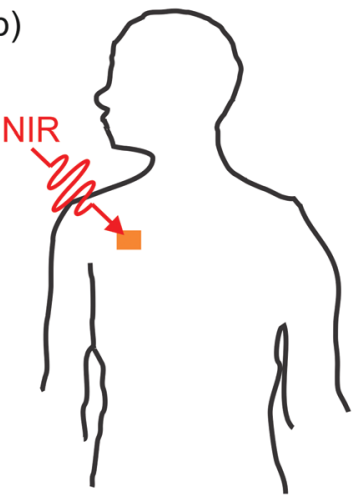

Fig. 2 (a) Tissue penetration depth of light with different wavelengths. NIR light penetrates deeper into tissue than UV and visible light. When the light wavelength further shifts to the IR region, the penetration depth decreases again because water absorbs IR light. (b) Near-infrared (NIR) light passes through tissue and induces photoreactions at surfaces of nano-carriers or implants in the body.

Recently, NIR photoreactions assisted by lanthanide-doped upconverting nanoparticles (UCNPs) have been developed (Fig. 3a). ${ }^{39,47}$ UCNPs are inorganic NPs which can convert NIR light to UV or visible light. ${ }^{48,49}$ The upconverted short-wavelength

(a)

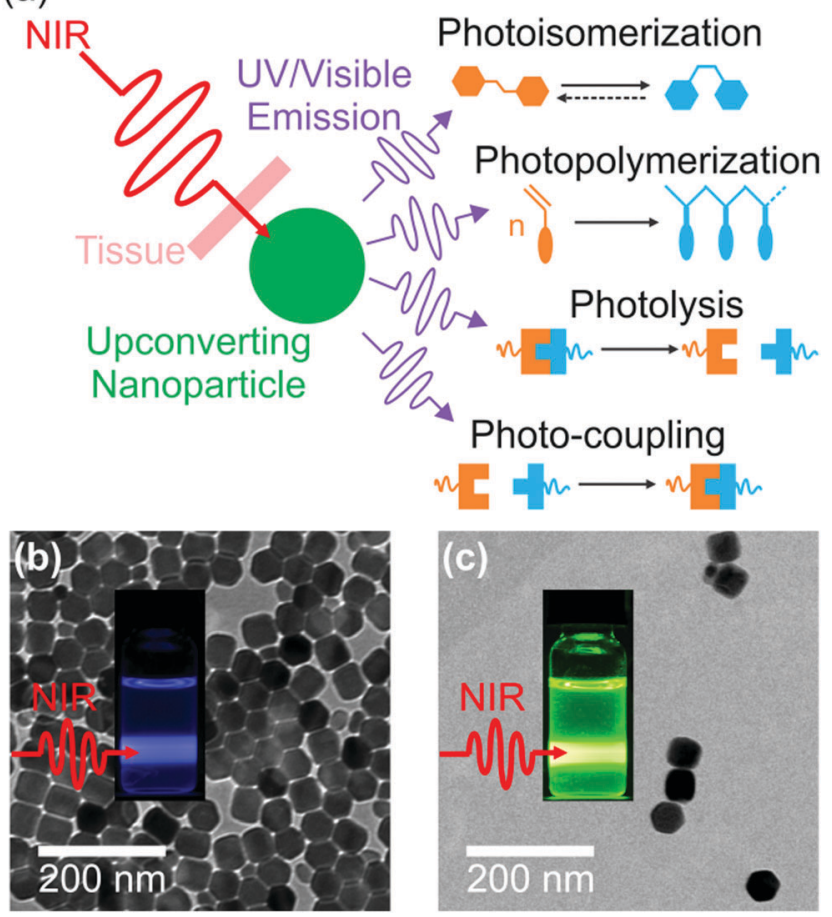

Fig. 3 (a) Schematic illustration of UCNP-assisted photochemistry. Four types of UCNP-assisted photoreactions including photoisomerization, photopolymerization, photolysis, and photo-coupling have been investigated. TEM images of (b) $\mathrm{NaYF}_{4}: \mathrm{Yb}_{\mathrm{Tm}} \mathrm{TmNaYF}$ (core $=\mathrm{NaYF}_{4}: 30 \mathrm{~mol} \%$ $\mathrm{Yb}^{3+} / 0.5 \mathrm{~mol} \% \mathrm{Tm}^{3+}$; shell $=\mathrm{NaYF}_{4}$ ) and (c) $\mathrm{NaYF}_{4}: \mathrm{Yb} /$ EraNaYF 4 (core = $\mathrm{NaYF}_{4}: 30 \mathrm{~mol} \% \mathrm{Yb}^{3+} / 2 \mathrm{~mol} \% \mathrm{Er}^{3+}$; shell $=\mathrm{NaYF}_{4}$ ) UCNPs. Insets in (b and c) are photographs of UCNPs upon a $980 \mathrm{~nm}$ laser exposure. Panels ( $b$ and $c$ ) adapted with permission. ${ }^{82}$ Copyright 2015, Wiley-VCH Verlag GmbH \& Co. KGaA. 
light can induce photoreactions of photosensitive compounds. This process is referred to as UCNP-assisted photochemistry. Compared with NIR photochemistry based on two-photon absorption, UCNP-assisted photoreactions are more efficient. The excitation intensity for UCNP-assisted photochemistry is several orders of magnitude lower than that for two-photon absorption. ${ }^{39}$ UCNP-assisted photoreactions are induced by inexpensive NIR laser diodes and do not require high-intensity, expensive femtosecond lasers. ${ }^{39}$ Additionally, it has been demonstrated that NIR light can induce UCNP-assisted photoreactions after passing through tissue with a thickness of a few millimeters. ${ }^{39}$ Moreover, UCNPs are highly stable under laser excitation.

We will not introduce the mechanism of photon upconversion and the synthesis of UCNPs in this perspective because there are comprehensive and very good reviews. ${ }^{4-53}$ Photodynamic therapy and NIR light-sensitive materials based on UCNPs have also been reviewed. ${ }^{39,54,55}$ In the current perspective article, we concentrate on UCNP-assisted photochemistry at interfaces, highlight some potential applications, and discuss future challenges.

\section{General concept of UCNP-assisted photochemistry}

In UCNP-assisted photochemistry, UCNPs convert NIR light to UV or visible light (Fig. 3). Two typical UCNPs, $\mathrm{NaYF}_{4}: \mathrm{Yb} / \mathrm{Tm}$ UCNPs $\left(\beta\right.$-phase $\mathrm{NaYF}_{4}$ doped with $\mathrm{Yb}^{3+}$ and $\mathrm{Tm}^{3+}$ ) and $\mathrm{NaYF}_{4}$ : $\mathrm{Yb} /$ Er UCNPs $\left(\beta\right.$-phase $\mathrm{NaYF}_{4}$ doped with $\mathrm{Yb}^{3+}$ and $\mathrm{Er}^{3+}$ ) are shown in Fig. $3 \mathrm{~b}$ and c. In these UCNPs, $\mathrm{Yb}^{3+}$ is the sensitizer which can harvest NIR light and transfer energy to $\mathrm{Tm}^{3+}$ or $\mathrm{Er}^{3+}$. The energy transfer process from $\mathrm{Yb}^{3+}$ to $\mathrm{Tm}^{3+}$ or $\mathrm{Er}^{3+}$ may occur for several times so that $\mathrm{Tm}^{3+}$ or $\mathrm{Er}^{3+}$ can be excited to a higher excited state. $\mathrm{Tm}^{3+}$ is a UV/blue emitter; $\mathrm{Er}^{3+}$ is a green/ red emitter.

The second important component for UCNP-assisted photochemistry is the photosensitive substance. Conventional photosensitive compounds are usually sensitive to UV or visible light but are not sensitive to NIR light because of their short absorption wavelengths. To make them NIR photosensitive, they are combined with UCNPs. The upconverted UV or visible light from UCNPs can induce photoreactions of conventional photosensitive compounds (Fig. 3a). A requirement for UCNPassisted photochemistry is that the emission wavelengths of UCNPs should overlap with the absorption wavelengths of photosensitive compounds. If photosensitive compounds are very close to UCNPs, energy transfer from excited UCNPs to photosensitive compounds may occur. Usually, photosensitive compounds re-absorb upconverted light which induces photoreactions.

UCNPs have assisted different types of photoreactions such as photoisomerization, ${ }^{47,56-65}$ photopolymerization, ${ }^{6-70}$ photolysis, $^{71-91}$ and photo-coupling ${ }^{92}$ (Fig. 3a). (1) UCNPassisted photoisomerization can be triggered reversibly using NIR light in the presence of UCNPs and photoswitchable compounds such as azobenzene derivatives, ${ }^{59,63}$ spiropyran derivatives, ${ }^{64,93}$ and dithienylethene derivatives. ${ }^{47,56}$ (2) UCNPassisted photopolymerization is useful to cure thick samples (up to $13.7 \mathrm{~cm}$ ). ${ }^{70}$ Different monomers have been polymerized under NIR light irradiation in the presence of photoinitiators and UCNPs. ${ }^{67}$ (3) UCNP-assisted photolysis is conducted by combining UCNPs with photolytic compounds including $o$-nitrobenzyl derivatives, ${ }^{72,73}$ coumarin derivatives, ${ }^{80,82} \mathrm{Ru}$ complexes, ${ }^{81-84,91}$ and other photocaged compounds. ${ }^{85-88}$ UCNP-assisted photolysis has been extensively studied because of its wide applications such as drug delivery, ${ }^{72}$ activation of sensors, ${ }^{74}$ and controlling protein adsorption and cell adhesion. $^{81,90}$ (4) UCNP-assisted photo-coupling is a new type of UCNP-assisted photoreactions, which was demonstrated by us and our collaborators very recently. ${ }^{92}$ These UCNP-assisted photoreactions at different interfaces will be discussed in the next sections.

\section{UCNP-assisted photochemistry at nanoparticle surfaces}

NIR light can trigger reactions of photosensitive compounds grafted on UCNPs (Fig. 4). Upon NIR irradiation, the grafted photosensitive compounds may absorb the upconverted light that induces photoreactions. The short distance between the grafted photosensitive compounds and UCNPs may allow nonradiative energy transfer from the excited UCNPs to the photosensitive compounds. Therefore, UCNP-assisted photoreactions at UCNP surfaces are usually more efficient than UCNP-assisted photoreactions in solution, where photosensitive compounds are far away from UCNPs.

The first UCNP-assisted photoreaction at UCNP surfaces was reported by Branda and co-workers. ${ }^{71}$ UCNPs were grafted with $3^{\prime}, 5^{\prime}$-di(carboxymethoxy)benzoin cage 1a (Fig. 5). UCNPs converted $980 \mathrm{~nm}$ NIR light into $290 \mathrm{~nm}$ UV light, which induced the release of the caged species on the UCNP surface. This work opened up the avenue of using UCNPs for NIR-controlled drug delivery, surface modification, and activation of sensors, prodrugs and targeting groups.

NIR light-induced release of caged species was used to activate cell targeting groups on UCNP surfaces (Fig. 6). ${ }^{77}$ To achieve phototargeting, the tumor-homing agent folate was caged with a photolytic $o$-nitrobenzyl group and grafted onto UCNPs. Upon NIR irradiation, the upconverted UV light uncaged the $o$-nitrobenzyl

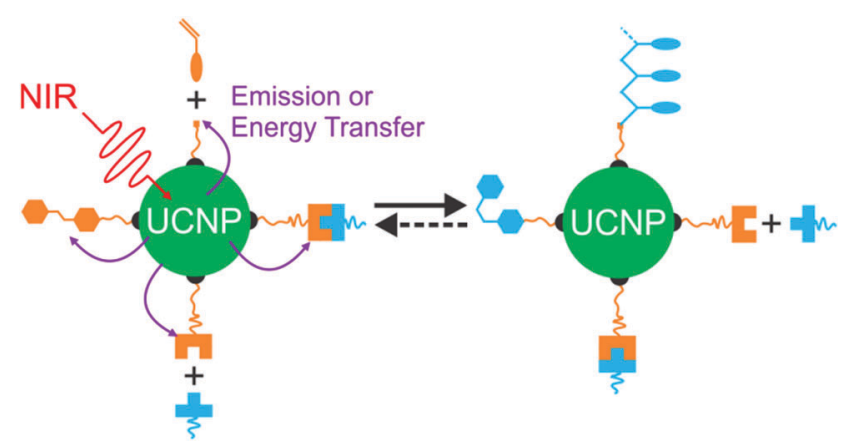

Fig. 4 Schematic illustration of UCNP-assisted photochemistry at NP surfaces. 


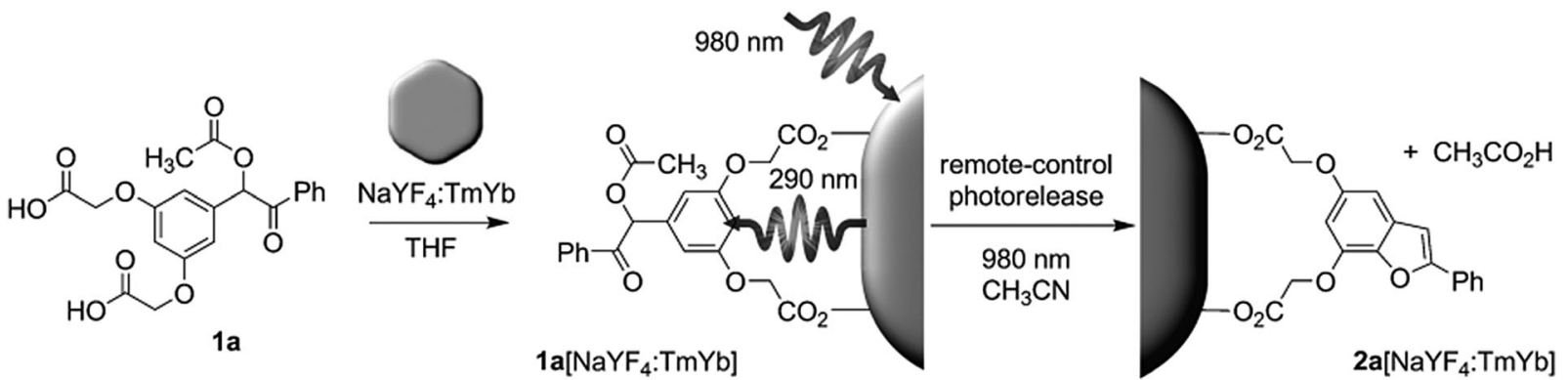

Fig. 5 UCNP-assisted photolysis at surfaces of UCNPs. Decoration of UCNPs with $3^{\prime}, 5^{\prime}$-di(carboxymethoxy)benzoin cage 1a produces the remote-

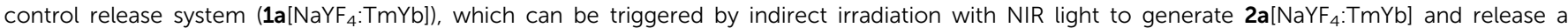
carboxylic acid. Reproduced with permission. ${ }^{71}$ Copyright 2010, Wiley-VCH Verlag GmbH \& Co. KGaA.

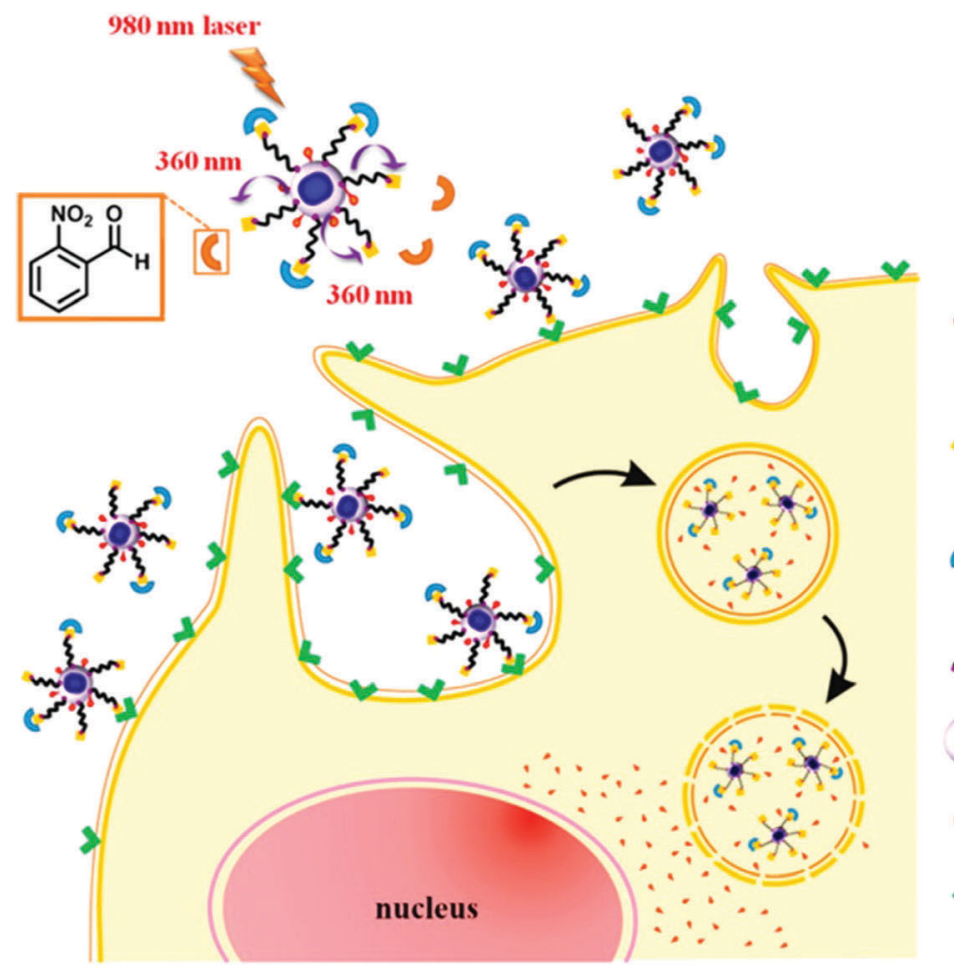

\section{doxorubicin}

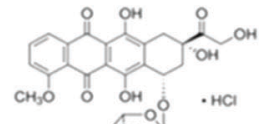

folic acid

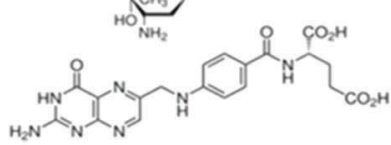

\section{2-nitrobenzylamine hydrochloride} (cage molecule)

PEG<smiles>CC(CCOCCC(=O)O)(CCC(=O)O)CC(C)(C)OCCNC(=O)CCC(=O)O</smiles>

\section{UCNPs $a \mathrm{SiO}_{2}$}

\section{2-nitrobenzaldehyde}

\section{folate receptor}

Fig. 6 Illustration of NIR-light-controlled targeting of cancer cells via UCNP-assisted photochemistry. Targeting of cancer cells can be achieved by the activation of the photocaged folic acids on the surfaces of the UCNPs using NIR light. Reproduced with permission.77 Copyright 2013 , American Chemical Society.

group and allowed folate-conjugated UCNPs to target cancer cells. After the UCNPs were taken up by cancer cells, the antitumor drug doxorubicin grafted on the surface of UCNPs via a disulfide bond was cleaved by lysosomal enzymes within the cancer cells. The released doxorubicin inhibited the growth of cancer cells. The photocaged UNCPs can serve as a platform for the improvement of selective targeting and reduction of side effects in cancer therapy.

Another application for UCNP-assisted photochemistry at NP surfaces is activation of fluorescent dyes for bioimaging (Fig. 7). ${ }^{74}$ Yang et al. demonstrated in vitro and in vivo uncaging and bioluminescence imaging based on photocaged UCNPs. A photocaged D-luciferin was conjugated to UCNPs. UCNPs upconverted NIR light into UV light, which uncaged the $o$-nitrobenzyl group from D-luciferin. As a result, the released D-luciferin effectively conferred enhanced fluorescence and bioluminescence signals. Shen et al. also used NIR light to activate a fluorescent dye grafted on UCNPs. ${ }^{76}$ Caged fluorescein, which can recover fluorescence upon removing the photolytic $o$-nitrobenzyl group, was grafted on UCNPs. UCNPs converted NIR light into UV light to uncage fluorescein in live cells. NIR photoactivation for enhanced bioimaging is an important technique that may offer new possibilities for analyzing cell lineages, probing cellular protein dynamics, and monitoring the dynamic functions of cells.

Several groups have constructed NIR-controlled drug delivery systems based on UCNP-assisted photochemistry at NP surfaces. ${ }^{60,62,79,83,85,86}$ For example, we coated UCNPs with a 
NIR

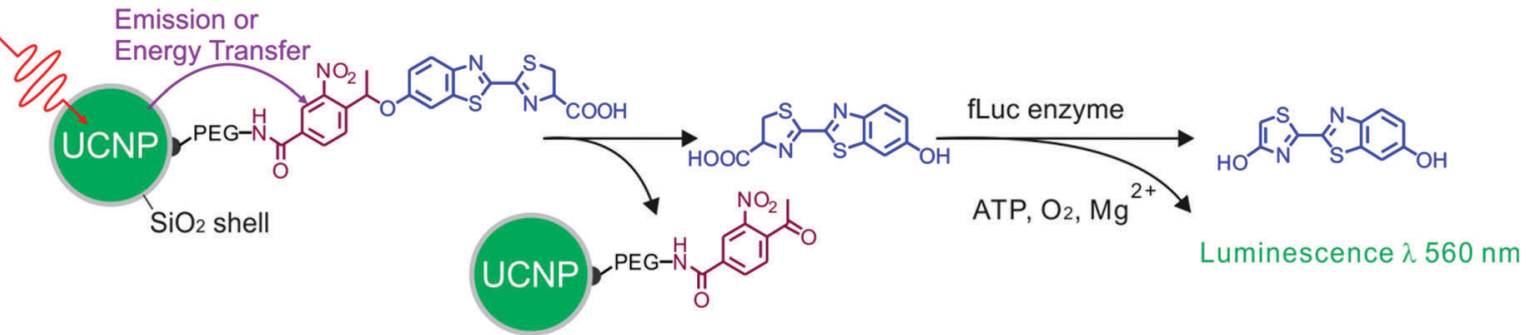

Fig. 7 UCNP-assisted photochemistry at surfaces of core/shell UCNPs for bioimaging. NIR light induced uncaging of D-luciferin and subsequent bioluminescence. Adapted with permission. ${ }^{74}$ Copyright 2012, Wiley-VCH Verlag GmbH \& Co. KGaA.

mesoporous silica shell, loaded the anticancer drug doxorubicin in the pores, and grafted photocleavable $\mathrm{Ru}$ complexes onto the NP surfaces (Fig. 8a). ${ }^{83}$ The Ru complexes acted as molecular valves, which prevented drug leakage. Upon NIR irradiation, the upconverted blue light induces cleavage of $\mathrm{Ru}$ complexes that releases the drug which inhibited cancer cells growth. The advantage of this system is that drug release was triggered by $974 \mathrm{~nm}$ light with an intensity as low as $0.35 \mathrm{~W} \mathrm{~cm}^{-2}$. Such a low light intensity minimized overheating problems and prevented photodamage to the biological system.

(a)
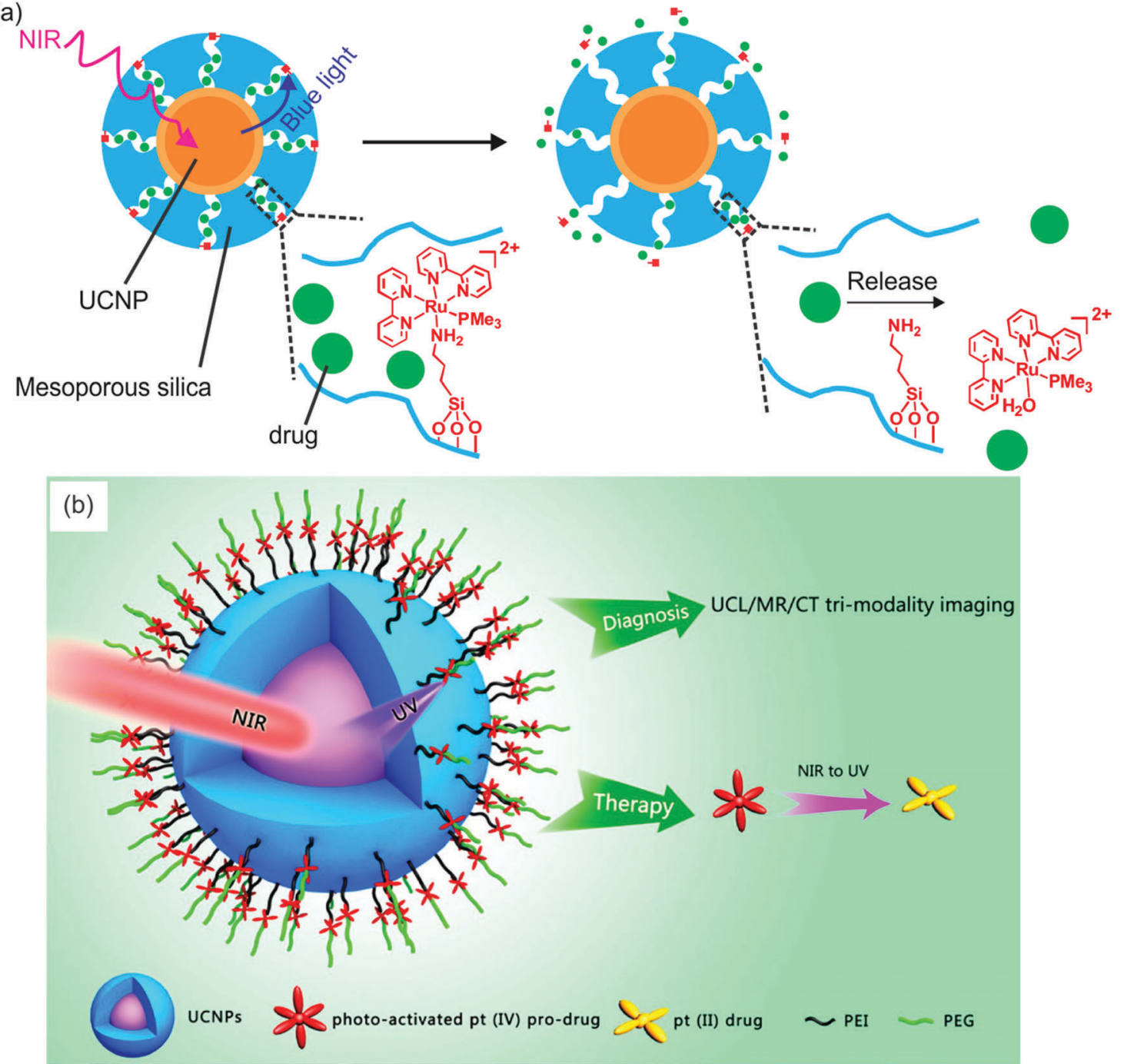

Fig. 8 UCNP-assisted photochemistry at NP surfaces for drug delivery. (a) NIR light-induced drug release using UCNP/mesoporous silica core/shell NPs functionalized with photocleavable Ru complexes. Under NIR excitation, the upconverted blue light triggers cleavage of the Ru complexes and release of the drug doxorubicin (green balls). (b) Schematic illustration of UCNPs functionalized with a photoactivated Pt(IV) prodrug. Panel (a) adapted with permission. ${ }^{83}$ Copyright 2015, Royal Society of Chemistry. Panel (b) reproduced with permission. ${ }^{85}$ Copyright 2013, American Chemical Society. 

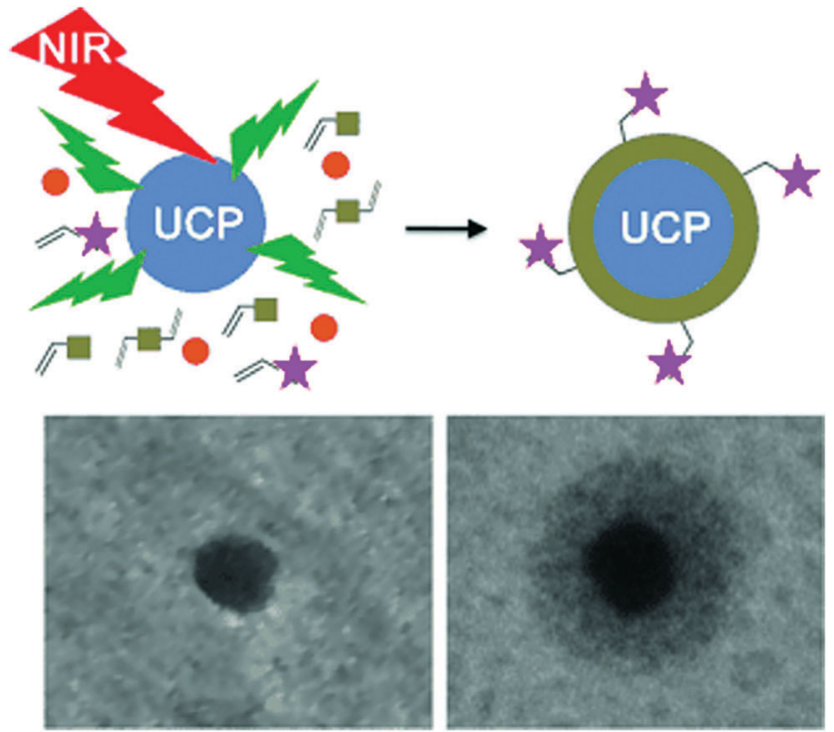

Fig. 9 UCNP-assisted photopolymerization at NP surfaces. Reproduced with permission. ${ }^{67}$ Copyright 2014, Wiley-VCH Verlag GmbH \& Co. KGaA.

In another drug delivery system, photoactivatable prodrugs have been grafted onto UCNPs for phototherapy. Dai et al. used NIR light to activate a $\mathrm{Pt}(\mathrm{Iv})$ prodrug grafted on $\mathrm{NaYF}_{4}: \mathrm{Yb}^{3+}$ / $\mathrm{Tm}^{3+} @ \mathrm{NaGdF}_{4}: \mathrm{Yb}^{3+}$ core-shell UCNPs (Fig. 8b). ${ }^{85}$ The UCNPs can effectively carry the grafted $\mathrm{Pt}(\mathrm{Iv})$ prodrugs into cancer cells by endocytosis. The mice treated with the NPs under NIR irradiation demonstrated better inhibition of tumor growth than those under direct UV irradiation. This system is multifunctional, which could be used for upconversion luminescence/ magnetic resonance/computer tomography trimodality imaging. Almost at the same time, Min et al. reported the conjugation of a similar photoactivatable Pt(Iv) prodrug to UCNPs. ${ }^{86}$ NIR light can activate the $\mathrm{Pt}$ (Iv) prodrug and simultaneously be used for real-time imaging of apoptosis induced by activated cytotoxicity.

UCNP-assisted photochemistry has also been used for surface coating. Haupt and co-workers demonstrated that UV or visible light emitted from UCNPs can be used to photopolymerize a thin polymer coating around the NPs for their protection, functionalization, and conjugation (Fig. 9). ${ }^{67}$ This approach enables to polymerize a large variety of monomers with different functionalities on UCNP surfaces. A second layer, exemplified by a molecularly imprinted polymer shell specific for trypsin, can also be synthesized. UCNP-assisted photopolymerization is easy to apply, rapid, and it allows different surface chemistries for further functionalization. Thus, this method provides a platform for the preparation of polymer-coated UCNPs for applications in bioassays, sensing, imaging, and drug delivery.

\section{UCNP-assisted photochemistry at surfaces of substrates}

UCNP-assisted photochemistry is also conducted at substrate surfaces (Fig. 10). To prepare an NIR photosensitive surface,

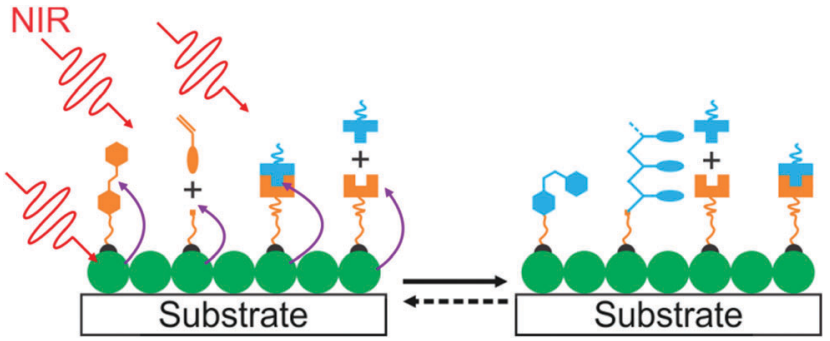

Fig. 10 Schematic illustration of UCNP-assisted photochemistry at the surface of a substrate.

UCNPs are deposited on a substrate. Photosensitive compounds are then grafted on the surface. Upon NIR excitation, the upconverted UV or visible light can trigger photoreactions at the surface.

Our group studied UCNP-assisted photocleavage of $\mathrm{Ru}$ complexes at a substrate surface (Fig. 11). ${ }^{81}$ In our design, proteins and an UCNP-decorated substrate were linked via blue-light-cleavable Ru complexes. The substrate was irradiated using NIR light with a photomask. In the exposed areas, UCNPs converted the NIR light into blue light, which induced cleavage of the $\mathrm{Ru}$ complexes and release of the proteins. Thus, protein adsorption on the surface can be controlled with NIR light. In addition, photon upconversion lithography is a general method for the patterning of biomaterials using NIR light. Patterned areas, as large as whole wafers, can be prepared using photon upconversion lithography. The smallest line width obtained was $\sim 15 \mu \mathrm{m}$. Thus, we envision using photon upconversion lithography to control cell migration, guide neuron development, and regulate inflammation and vascularization of biomaterials. In this work, quartz and silicon wafers were used as model substrates. Our ongoing work in this direction is to fabricate implants with similar surfaces for NIR light-controlled surface properties for in vivo applications.

UCNP-assisted photochemistry also showed applications in NIR-controlled cell adhesion. One successful example is the work of Qu and co-workers (Fig. 12a). ${ }^{90}$ They fabricated an UCNP-decorated substrate. A UV-photocleavable 4-(hydroxymethyl)3-nitrobenzoic acid group and a cell adhesive RGD ligand were grafted on the surface. Cells can adhere on such a surface. To detach cells from this surface, UCNPs harvested NIR light and convert it into local UV light, which resulted in cleavage of the photocleavable linkers and on-demand release of the cells. The authors also demonstrated that NIR light passed through $4 \mathrm{~mm}$-thick tissue and controlled cell adhesion on the substrate. By liking UCNPs and gene nano-carriers with the same photolytic linker, Zheng et al. demonstrated NIR light-controlled gene selective expression. ${ }^{94}$ Both studies have demonstrated that this approach facilitates the design of UCNP-based multifunctional cell scaffold for dynamic study of biological process, regeneration medicine, and disease-related cell isolation and analysis.

The above-mentioned work demonstrated irreversible control of cell adhesion on a substrate using NIR light. To achieve reversible control, photoswitchable spiropyran was grafted on UCNP-modified substrates (Fig. 12b). ${ }^{65}$ It is well known that the spiropyran-to-merocyanine isomerization is induced using 
(a)
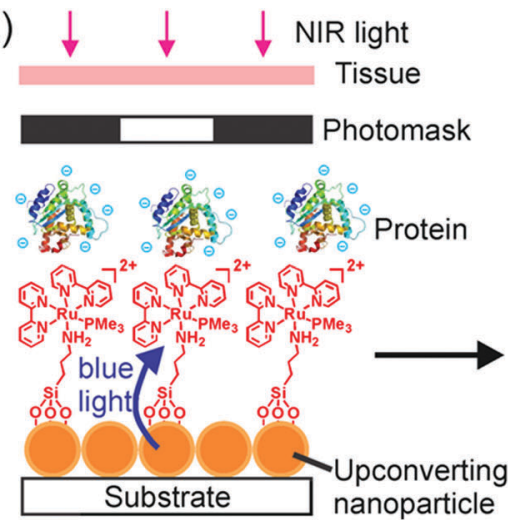

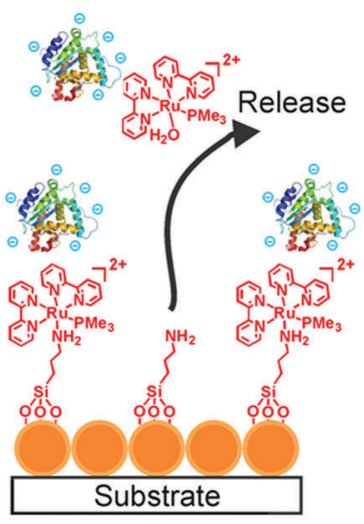

(b)

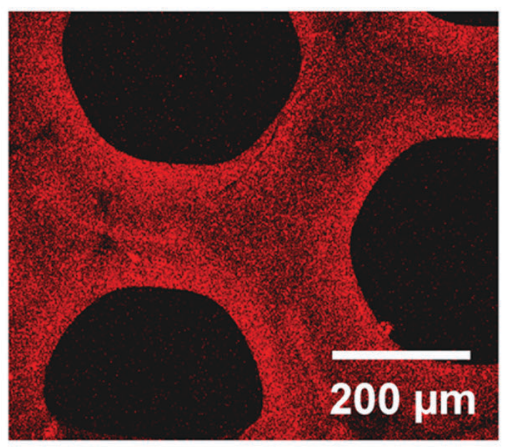

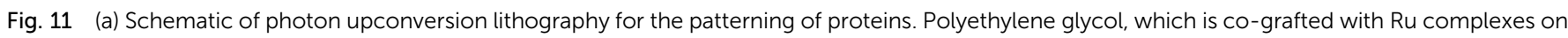

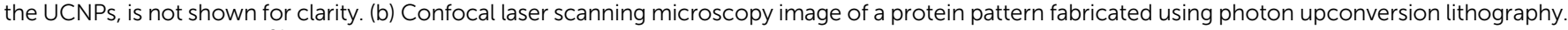
Adapted with permission. ${ }^{81}$ Copyright 2015, Wiley-VCH Verlag GmbH \& Co. KGaA.

UV light and merocyanine-to-spiropyran back isomerization is induced using green light. $\mathrm{Qu}$ and co-workers synthesized $\mathrm{NaYF}_{4}: \mathrm{Tm} / \mathrm{Yb} @ \mathrm{NaYF}_{4} @ \mathrm{NaYF}_{4}: \mathrm{Er} / \mathrm{Yb} @ \mathrm{NaYF}_{4}$ core-shell-shellshell UCNPs, which emit more UV light under the excitation of high-intensity $980 \mathrm{~nm}$ light (e.g., $8 \mathrm{~W} \mathrm{~cm}^{-2}$ ) and emit more green light under the excitation of low-intensity $980 \mathrm{~nm}$ light (e.g., $\left.0.5 \mathrm{~W} \mathrm{~cm}^{-2}\right){ }^{65}$ Thus, the two-way isomerization of spiropyran on the UCNPs merely depends on the excitation intensity. At a high intensity, the spiropyran-to-merocyanine isomerization was prominent, whereas its reverse isomerization occurred upon irradiation by the same laser but with a lower intensity. Such NIR-controlled reversible isomerization made the interactions between surface-grafted spiropyran and cell surface protein fibronectin switchable, thus leading to reversible cell adhesion and detachment. Moreover, efficient adhesion-and-detachment of cells was realized even after 10 cycles. NIR light showed little damage toward cells and could control cell adhesion after passing through 4 mm-thick tissue. This approach is promising for in vivo dynamically manipulating cell-molecule interactions and biological processes.

\section{UCNP-assisted photochemistry at liquid/liquid interfaces}

NIR light can also trigger UCNP-assisted photoreactions at liquid/liquid interfaces. Recently, Chen et al. demonstrated UCNPassisted photoisomerization at water/oil interfaces (Fig. 13). ${ }^{95}$ UCNPs conjugated with photoswitchable spiropyran was hydrophobic. Light can reversibly control hydrophobicity/hydrophilicity of the NPs (Fig. 13d). UCNPs converted NIR light to UV light, which induced spiropyran-to-merocyanine isomerization and hydrophobic-to-hydrophilic transition. Subsequently, visible light induced the reverse merocyanine-to-spiropyran
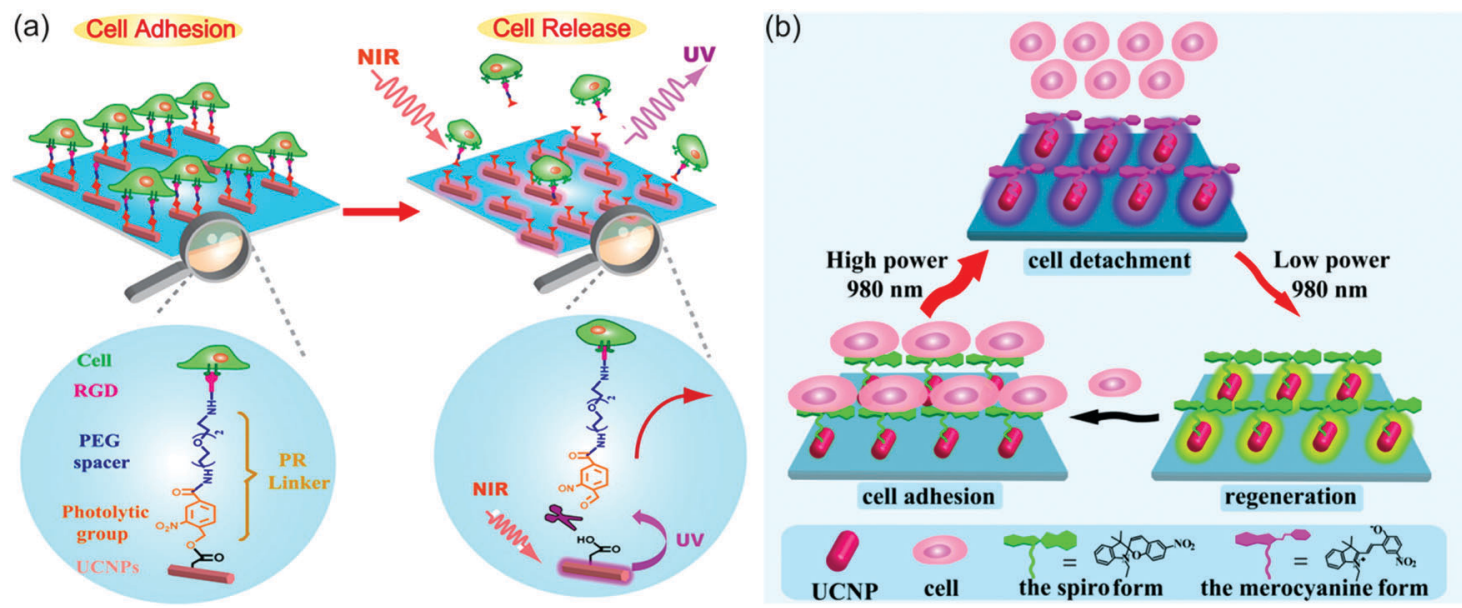

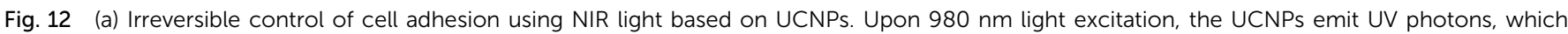

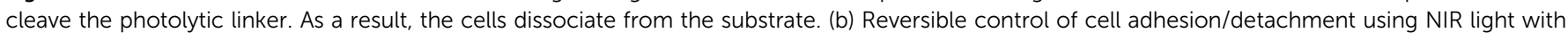

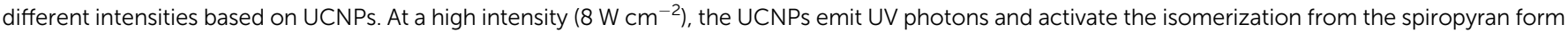

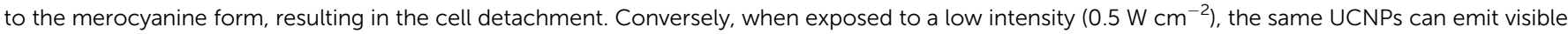

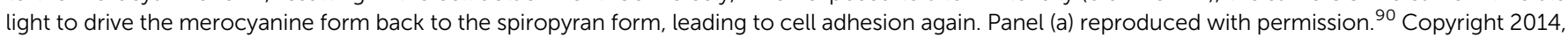
American Chemical Society. Panel (b) reproduced with permission. ${ }^{65}$ Copyright 2015, American Chemical Society. 
(a) Oil

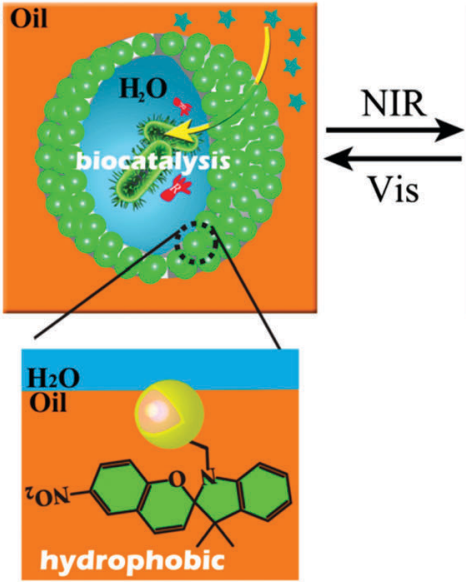

UCNP@SiO2

Microbe
* $(R, S)$-mandelonitrile

$R$-(-)-mandelic acid

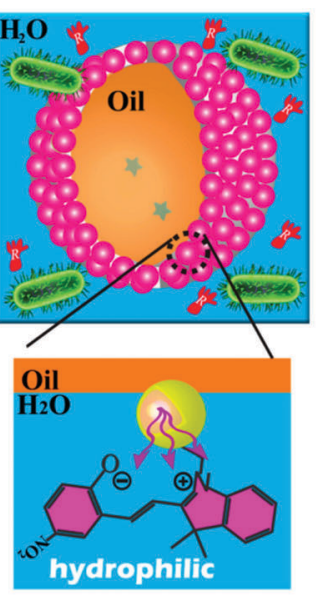

UV emission from UCNPs (b)

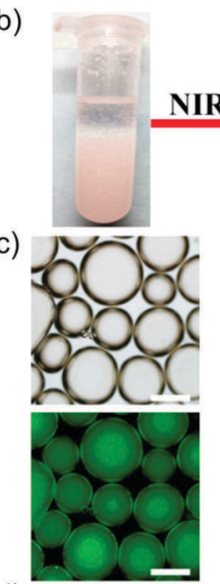

(d)

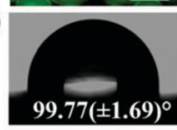

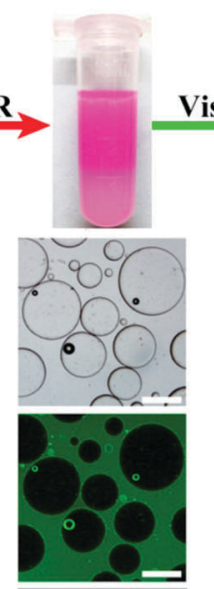

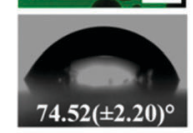

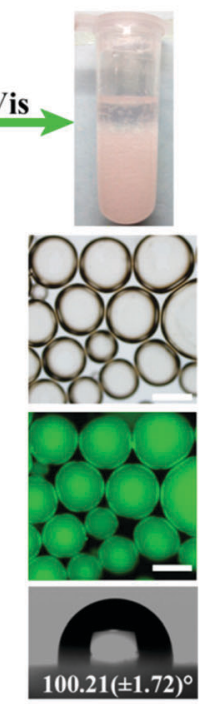

Fig. 13 (a) Schematic illustration of the NIR light-responsive Pickering emulsions with reversible inversion ability for biphasic enantioselective biocatalysis. (b) Photograph of Pickering emulsions stabilized by spiropyran-conjugated UCNPs: w/o (left), o/w (middle), and w/o (right) before and after the irradiation of light with different wavelengths. (c) Fluorescence microscopy images of the corresponding Pickering emulsions shown in (b) (scale bar: $200 \mu \mathrm{m}$ ). (d) Water contact angles on a filter paper deposited with spiropyran-conjugated UCNPs irradiated using light with wavelengths. Reproduced with permission. ${ }^{95}$ Copyright 2014, American Chemical Society.

isomerization and hydrophilic-to-hydrophobic transition. Similar to other colloids, ${ }^{96,97}$ the spiropyran-conjugated UCNPs with interfacial activity are suitable to prepare Pickering emulsions. The Pickering emulsions stabilized by spiropyran-conjugated UCNPs can be inversed under light irradiation (Fig. 13b and c). Spiropyran-conjugated UCNPs can stabilize water-in-oil (w/o) emulsions at the bottom of the sample and prevent sedimentation (Fig. 13b, left). Upon NIR irradiation and homogenization, spiropyran-conjugated UCNPs transferred to the upper layer and oil-in-water $(\mathrm{o} / \mathrm{w})$ emulsions were formed (Fig. 13b, middle). Spiropyran-conjugated UCNPs could transfer back to the bottom layer after exposing to visible light and shaking (Fig. 13b, right). A model enantioselective biocatalytic active bacterium was loaded in the aqueous phase (Fig. 13a). The Pickering emulsion enhanced the catalytic performance. In addition, product recovery, and biocatalysts and colloid emulsifiers recycling could be easily realized based on the light-controlled inversion of the Pickering emulsion. Importantly, the utilization of NIR/visible light to perform the reversible inversion without any chemical auxiliaries showed little damage toward the biocatalysts, which was highlighted by the high catalytic efficiency and high enantioselectivity even after 10 cycles. NIR/visible light controlled Pickering emulsions showed promising potential for biocatalysis in biphasic systems.

Another example of UCNP-assisted photochemistry at interfaces is NIR light-induced photoisomerization in the bilayer membranes of vesicles (Fig. 14). ${ }^{98}$ Phospholipid modified UCNPs and the anticancer drug DOX were encapsulated in azobenzene-doped liposomes. NIR light can be converted into UV and visible light to trigger photoisomerization of azobenzene amphiphiles, which resulted in drug release. The release amount and rate of the anticancer drug can be well

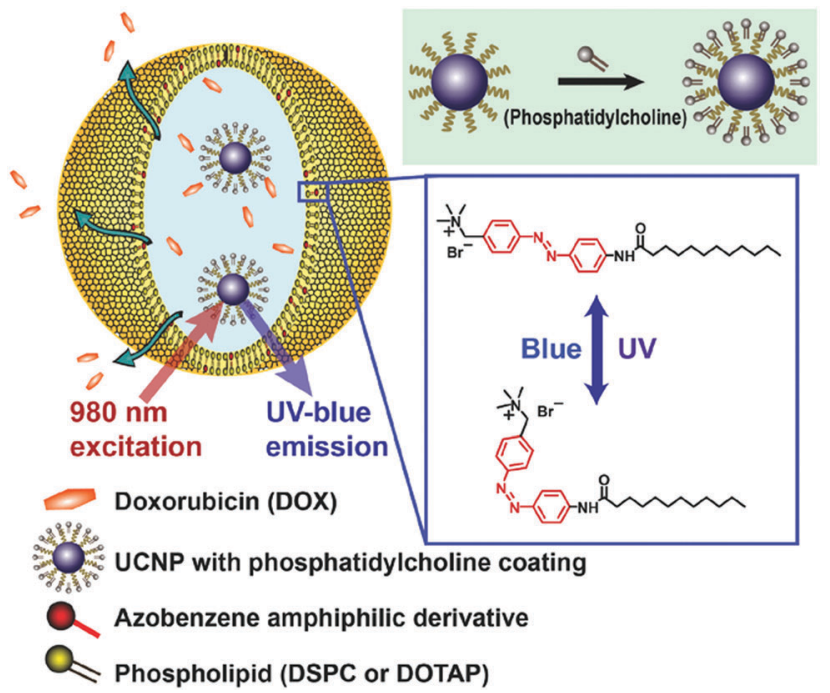

Fig. 14 Schematic illustration of the NIR-triggered azobenzene-liposome/ UCNP hybrid vesicles for controlled drug delivery. The phosphatidylcholine coated UCNPs and the anticancer drug DOX are loaded together within the hydrophilic compartment of the liposome. The amphiphilic azobenzene derivatives are embedded in the liposome bilayers consisting of phospholipids (DSPC/DOTAP). Reproduced with permission. ${ }^{98}$ Copyright 2016 , Wiley-VCH Verlag GmbH \& Co. KGaA.

controlled by tuning the intensity and duration of the NIR laser. The NIR light-triggered drug release ability makes this novel drug delivery system an effective chemotherapy to overcome multidrug resistance by spatiotemporal control. This drug delivery system provides great values in the advancement of clinical NIR light-regulated precise drug release and drugresistant tumor treatment. 


\section{Outlook}

From the chemistry point of view, it is interesting to develop new NIR photoreactions at interfaces based on UCNPs. UCNPassisted photoisomerization, photolysis, and photopolymerization at interfaces have been extensively studied and some potential applications have been demonstrated. In contrast, UCNP-assisted photo-coupling reactions have been reported by us and our collaborators only recently; ${ }^{92}$ this type of reactions has not been widely investigated (Fig. 15). We envision the use of UCNP-assisted photo-coupling reactions to modify biointerfaces. A possible application is NIR light-induced NP coupling, which can result in NP aggregates with enhanced therapeutic effects due to the size effect. ${ }^{99}$ Another possible application of UCNP-assisted photo-coupling reactions at interfaces is to glue biological tissues with NIR light. ${ }^{100}$

Improving spatial resolution of photon upconversion lithography for the patterning of biomaterials is still a challenge. Two-photon lithography is a standard technique in some labs and in industry to fabricate patterns with a feature size of a few hundred nanometers. However, the smallest feature size fabricated by photon upconversion lithography is only $\sim 15 \mu \mathrm{m} .{ }^{81}$ It is too large for some studies on interactions between patterned biomolecules and cells. ${ }^{101}$ It is highly desirable to improve the spatial resolution of photon upconversion lithography. We and our collaborators have shown that the spatial resolution of upconversion can be improved using pulsed excitation because pulsed excitation can avoid saturation in the upconversion process. ${ }^{102}$ This technique has been adapted to high-resolution photopatterning by us, which will be reported in due course.

NIR-controlled cell adhesion based on UCNPs has been demonstrated and is promising for in vivo applications. The next step in this direction would be guide cell migration and stem cell fate. Currently, light-guided cell migration and stem cell fate are based on UV photopatterning or two-photon lithography. ${ }^{38,103}$ Photon upconversion lithography with the spatial solution of tens of $\mu \mathrm{m}$ should be suitable for these applications.

UCNP-assisted photochemistry at interfaces still faces some problems that may hinder its applications. A big problem for UCNP-assisted photochemistry is photothermal overheating. The quantum yield of UCNPs is usually less than $1 \%{ }^{104}$ To obtain sufficient UV or visible light for photoreactions, UCNPs are excited by high-intensity NIR light; typical excitation

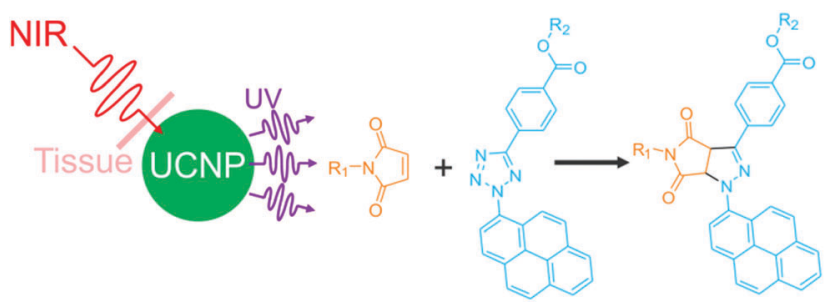

Fig. 15 NIR photo-coupling reaction based on nitrile imine-mediated tetrazole-ene cycloadditions in the presence of UCNPs. This type of photoreaction at interfaces still awaits exploration. intensities at $980 \mathrm{~nm}$ are $0.35-560 \mathrm{~W} \mathrm{~cm}{ }^{-2} \cdot{ }^{39}$ Because the maximum permissible exposure for skin at $980 \mathrm{~nm}$ is $\sim 0.726 \mathrm{~W} \mathrm{~cm}^{-2},{ }^{105,106}$ high-intensity $980 \mathrm{~nm}$ light can overheat and damage biological systems. ${ }^{82}$ We and others partially addressed the overheating problem using $\mathrm{Ru}$ complexes as photosensitive compounds, ${ }^{82,83}$ high-efficient UCNPs ${ }^{76}$ and UCNPs that can be excited by $808 \mathrm{~nm}$ light. ${ }^{107-112}$ Although NIR light at $980 \mathrm{~nm}$ is better suited than UV light for biomedical applications, NIR light at $808 \mathrm{~nm}$ is even better because the penetration depth of $808 \mathrm{~nm}$ light in bovine tissue is $54 \%$ deeper than that of $980 \mathrm{~nm}$ light. ${ }^{41}$ The development of highly efficient UCNPs, which can be excited with $808 \mathrm{~nm}$ light, is currently a topic of intense investigation. At the moment, different strategies are under investigation to enhance the efficiency of upconversion. ${ }^{113}$ In particular, enhancing upconversion using surface plasmons and photonic structures is a topic under intense investigation because of the potential to achieve large enhancement. ${ }^{114-119}$ Different strategies might be combined in a system to optimize upconversion efficiency and minimize the overheating problem for deep-tissue applications.

Another interesting application of UCNP-assisted photochemistry at interfaces is photovoltaics such as solar cells. ${ }^{120-123}$ The incorporation of UCNPs into dye-sensitized solar cells enables the use of the NIR region of the solar spectrum. ${ }^{120-123}$ This design requires the development of highly efficient UCNPs that can be excited by broadband NIR light.

\section{Acknowledgements}

S. W. acknowledges the Deutsche Forschungsgemeinschaft (DFG, WU 787/2-1) and the Fonds der Chemischen Industrie (FCI, No. 661548) for their financial support. H.-J. B. acknowledges financial support from the ERC advanced grant 340391-SuPro. Open Access funding provided by the Max Planck Society.

\section{References}

1 J. X. Cui, V. San Miguel and A. del Campo, Macromol. Rapid Commun., 2013, 34, 310-329.

2 S. T. Wang, Y. L. Song and L. Jiang, J. Photochem. Photobiol., C, 2007, 8, 18-29.

3 M. Paven, H. Mayama, T. Sekido, H. J. Butt, Y. Nakamura and S. Fujii, Adv. Funct. Mater., 2016, 26, 3199-3206.

4 K. Ichimura, S. K. Oh and M. Nakagawa, Science, 2000, 288, 1624-1626.

5 E. Blasco, M. Piñol, L. Oriol, B. V. K. J. Schmidt, A. Welle, V. Trouillet, M. Bruns and C. Barner-Kowollik, Adv. Funct. Mater., 2013, 23, 4011-4019.

6 C. Li, Y. Y. Zhang, J. Ju, F. T. Cheng, M. J. Liu, L. Jiang and Y. L. Yu, Adv. Funct. Mater., 2012, 22, 760-763.

7 J. X. Cui, T. H. Nguyen, M. Ceolin, R. Berger, O. Azzaroni and A. del Campo, Macromolecules, 2012, 45, 3213-3220.

8 R. Barbey, L. Lavanant, D. Paripovic, N. Schuwer, C. Sugnaux, S. Tugulu and H. A. Klok, Chem. Rev., 2009, 109, 5437-5527. 
9 J. T. Huang, S. Wu, S. Beckemper, A. Gillner, Q. J. Zhang and K. Y. Wang, Opt. Lett., 2010, 35, 2711-2713.

10 J. T. Huang, S. Beckemper, S. Wu, J. Shen, Q. J. Zhang, K. Y. Wang and A. Gillner, Phys. Chem. Chem. Phys., 2011, 13, 16150-16158.

11 R. Rosario, D. Gust, M. Hayes, F. Jahnke, J. Springer and A. A. Garcia, Langmuir, 2002, 18, 8062-8069.

12 J. Groten, C. Bunte and J. Rühe, Langmuir, 2012, 28, 15038-15046.

13 S. Wu and J. T. Huang, RSC Adv., 2012, 2, 12084-12087.

14 P. Weis, D. S. Wang and S. Wu, Macromolecules, 2016, 49, 6368-6373.

15 T. Pauloehrl, G. Delaittre, M. Bruns, M. Meissler, H. G. Borner, M. Bastmeyer and C. Barner-Kowollik, Angew. Chem., Int. Ed., 2012, 51, 9181-9184.

16 H. Zhou, C. Xue, P. Weis, Y. Suzuki, S. Huang, K. Koynov, G. K. Auernhammer, R. Berger, H. J. Butt and S. Wu, Nat. Chem., 2017, 9, 145-151.

17 J. Nishida, M. Kobayashi and A. Takahara, ACS Macro Lett., 2013, 2, 112-115.

18 M. Suda, N. Kameyama, A. Ikegami and Y. Einaga, J. Am. Chem. Soc., 2009, 131, 865-870.

19 A. Ikegami, M. Suda, T. Watanabe and Y. Einaga, Angew. Chem., Int. Ed., 2010, 49, 372-374.

20 D. S. Wang and S. Wu, Langmuir, 2016, 32, 632-636.

21 N. C. Fan, F. Y. Cheng, J. A. Ho and C. S. Yeh, Angew. Chem., Int. Ed., 2012, 51, 8806-8810.

22 R. Klajn, P. J. Wesson, K. J. M. Bishop and B. A. Grzybowski, Angew. Chem., Int. Ed., 2009, 48, 7035-7039.

23 H. Zhao, S. Sen, T. Udayabhaskararao, M. Sawczyk, K. Kucanda, D. Manna, P. K. Kundu, J. W. Lee, P. Kral and R. Klajn, Nat. Nanotechnol., 2016, 11, 82-88.

24 Y. Zhou, D. S. Wang, S. L. Huang, G. Auernhammer, Y. J. He, H. J. Butt and S. Wu, Chem. Commun., 2015, 51, 2725-2727.

25 A. Diguet, R. M. Guillermic, N. Magome, A. Saint-Jalmes, Y. Chen, K. Yoshikawa and D. Baigl, Angew. Chem., Int. Ed., 2009, 48, 9281-9284.

26 L. D. Zarzar, V. Sresht, E. M. Sletten, J. A. Kalow, D. Blankschtein and T. M. Swager, Nature, 2015, 518, 520-524.

27 N. Kavokine, M. Anyfantakis, M. Morel, S. Rudiuk, T. Bickel and D. Baigl, Angew. Chem., Int. Ed., 2016, 55, 11183-11187.

28 X. Wang, G. Liu, J. Hu, G. Zhang and S. Liu, Angew. Chem., Int. Ed., 2014, 53, 3138-3142.

29 Y. R. Choi, G. C. Kim, H.-G. Jeon, J. Park, W. Namkung and K.-S. Jeong, Chem. Commun., 2014, 50, 15305-15308.

30 A. Diguet, M. Yanagisawa, Y. J. Liu, E. Brun, S. Abadie, S. Rudiuk and D. Baigl, J. Am. Chem. Soc., 2012, 134, 4898-4904.

31 W. Su, Y. H. Luo, Q. Yan, S. Wu, K. Han, Q. J. Zhang, Y. Q. Gu and Y. M. Li, Macromol. Rapid Commun., 2007, 28, 1251-1256.

32 M. Anyfantakis and D. Baigl, Angew. Chem., Int. Ed., 2014, 53, 14077-14081.
33 S. N. Varanakkottu, M. Anyfantakis, M. Morel, S. Rudiuk and D. Baigl, Nano Lett., 2016, 16, 644-650.

34 M. Schutt, S. S. Krupka, A. G. Milbradt, S. Deindl, E. K. Sinner, D. Oesterhelt, C. Renner and L. Moroder, Chem. Biol., 2003, 10, 487-490.

35 J. Auernheimer, C. Dahmen, U. Hersel, A. Bausch and H. Kessler, J. Am. Chem. Soc., 2005, 127, 16107-16110.

36 J. Edahiro, K. Sumaru, Y. Tada, K. Ohi, T. Takagi, M. Kameda, T. Shinbo, T. Kanamori and Y. Yoshimi, Biomacromolecules, 2005, 6, 970-974.

37 S. Petersen, J. M. Alonso, A. Specht, P. Duodu, M. Goeldner and A. del Campo, Angew. Chem., Int. Ed., 2008, 47, 3192-3195.

38 T. T. Lee, J. R. Garcia, J. I. Paez, A. Singh, E. A. Phelps, S. Weis, Z. Shafiq, A. Shekaran, A. del Campo and A. J. Garcia, Nat. Mater., 2015, 14, 352-360.

39 S. Wu and H. J. Butt, Adv. Mater., 2016, 28, 1208-1226.

40 P. Juzenas, A. Juzeniene, O. Kaalhus, V. Iani and J. Moan, Photochem. Photobiol. Sci., 2002, 1, 745-748.

41 D. E. Hudson, D. O. Hudson, J. M. Wininger and B. D. Richardson, Photomed. Laser Surg., 2013, 31, 163-168.

42 R. Steiner, in Laser and IPL Technology in Dermatology and Aesthetic Medicine, ed. C. Raulin and S. Karsai, Springer Berlin Heidelberg, 2011, ch. 2, pp. 23-36, DOI: 10.1007/ 978-3-642-03438-1_2.

43 T. Furuta, S. S. H. Wang, J. L. Dantzker, T. M. Dore, W. J. Bybee, E. M. Callaway, W. Denk and R. Y. Tsien, Proc. Natl. Acad. Sci. U. S. A., 1999, 96, 1193-1200.

44 M. Alvarez, A. Best, S. Pradhan-Kadam, K. Koynov, U. Jonas and M. Kreiter, Adv. Mater., 2008, 20, 4563-4567.

45 M. Alvarez, A. Best, A. Unger, J. M. Alonso, A. del Campo, M. Schmelzeisen, K. Koynov and M. Kreiter, Adv. Funct. Mater., 2010, 20, 4265-4272.

46 T. M. Guardado-Alvarez, L. Sudha Devi, M. M. Russell, B. J. Schwartz and J. I. Zink, J. Am. Chem. Soc., 2013, 135, 14000-14003.

47 C. J. Carling, J. C. Boyer and N. R. Branda, J. Am. Chem. Soc., 2009, 131, 10838-10839.

48 J. A. Capobianco, F. Vetrone, T. D'Alesio, G. Tessari, A. Speghini and M. Bettinelli, Phys. Chem. Chem. Phys., 2000, 2, 3203-3207.

49 M. Haase and H. Schafer, Angew. Chem., Int. Ed., 2011, 50, 5808-5829.

50 Z. Y. Cheng and J. Lin, Macromol. Rapid Commun., 2015, 36, 790-827.

51 F. Auzel, Chem. Rev., 2004, 104, 139-173.

52 F. Wang and X. G. Liu, Chem. Soc. Rev., 2009, 38, 976-989.

53 J. Zhou, Q. Liu, W. Feng, Y. Sun and F. Y. Li, Chem. Rev., 2015, 115, 395-465.

54 N. M. Idris, M. K. G. Jayakumar, A. Bansal and Y. Zhang, Chem. Soc. Rev., 2015, 44, 1449-1478.

55 S. Wu, J. Blinco and C. Barner-Kowollik, Chem. - Eur. J., 2017, DOI: 10.1002/chem.201700658.

56 J. C. Boyer, C. J. Carling, B. D. Gates and N. R. Branda, J. Am. Chem. Soc., 2010, 132, 15766-15772.

57 T. Q. Wu, M. Barker, K. M. Arafeh, J. C. Boyer, C. J. Carling and N. R. Branda, Angew. Chem., Int. Ed., 2013, 52, 11106-11109. 
58 L. Wang, H. Dong, Y. N. Li, R. Liu, Y. F. Wang, H. K. Bisoyi, L. D. Sun, C. H. Yan and Q. Li, Adv. Mater., 2015, 27, 2065-2069.

59 W. Wu, L. M. Yao, T. S. Yang, R. Y. Yin, F. Y. Li and Y. L. Yu, J. Am. Chem. Soc., 2011, 133, 15810-15813.

60 J. A. Liu, W. B. Bu, L. M. Pan and J. L. Shi, Angew. Chem., Int. Ed., 2013, 52, 4375-4379.

61 J. N. Liu, J. W. Bu, W. B. Bu, S. J. Zhang, L. M. Pan, W. P. Fan, F. Chen, L. P. Zhou, W. J. Peng, K. L. Zhao, J. L. Du and J. L. Shi, Angew. Chem., Int. Ed., 2014, 53, 4551-4555.

62 X. M. Li, L. Zhou, Y. Wei, A. M. El-Toni, F. Zhang and D. Y. Zhao, J. Am. Chem. Soc., 2014, 136, 15086-15092.

63 L. Wang, H. Dong, Y. N. Li, C. M. Xue, L. D. Sun, C. H. Yan and Q. Li, J. Am. Chem. Soc., 2014, 136, 4480-4483.

64 B. F. Zhang, M. Frigoli, F. Angiuli, F. Vetrone and J. A. Capobianco, Chem. Commun., 2012, 48, 7244-7246.

65 W. Li, Z. Chen, L. Zhou, Z. Li, J. Ren and X. Qu, J. Am. Chem. Soc., 2015, 137, 8199-8205.

66 A. Stepuk, D. Mohn, R. N. Grass, M. Zehnder, K. W. Kramer, F. Pelle, A. Ferrier and W. J. Stark, Dent. Mater., 2012, 28, 304-311.

67 S. Beyazit, S. Ambrosini, N. Marchyk, E. Palo, V. Kale, T. Soukka, B. T. S. Bui and K. Haupt, Angew. Chem., Int. Ed., 2014, 53, 8919-8923.

68 Q. B. Xiao, Y. T. Ji, Z. H. Xiao, Y. Zhang, H. Z. Lin and Q. B. Wang, Chem. Commun., 2013, 49, 1527-1529.

69 J. Mendez-Ramos, J. C. Ruiz-Morales, P. Acosta-Mora and N. M. Khaidukov, J. Mater. Chem. C, 2016, 4, 801-806.

70 R. Liu, H. Chen, Z. Q. Li, F. Shi and X. Y. Liu, Polym. Chem., 2016, 7, 2457-2463.

71 C. J. Carling, F. Nourmohammadian, J. C. Boyer and N. R. Branda, Angew. Chem., Int. Ed., 2010, 49, 3782-3785.

72 B. Yan, J. C. Boyer, N. R. Branda and Y. Zhao, J. Am. Chem. Soc., 2011, 133, 19714-19717.

73 B. Yan, J. C. Boyer, D. Habault, N. R. Branda and Y. Zhao, J. Am. Chem. Soc., 2012, 134, 16558-16561.

74 Y. M. Yang, Q. Shao, R. R. Deng, C. Wang, X. Teng, K. Cheng, Z. Cheng, L. Huang, Z. Liu, X. G. Liu and B. G. Xing, Angew. Chem., Int. Ed., 2012, 51, 3125-3129.

75 M. K. G. Jayakumar, N. M. Idris and Y. Zhang, Proc. Natl. Acad. Sci. U. S. A., 2012, 109, 8483-8488.

76 J. Shen, G. Y. Chen, T. Y. Ohulchanskyy, S. J. Kesseli, S. Buchholz, Z. P. Li, P. N. Prasad and G. Han, Small, 2013, 9, 3213-3217.

77 Y. H. Chien, Y. L. Chou, S. W. Wang, S. T. Hung, M. C. Liau, Y. J. Chao, C. H. Su and C. S. Yeh, ACS Nano, 2013, 7, 8516-8528.

78 M. L. Viger, M. Grossman, N. Fomina and A. Almutairi, Adv. Mater., 2013, 25, 3733-3738.

79 Y. M. Yang, B. Velmurugan, X. G. Liu and B. G. Xing, Small, 2013, 9, 2937-2944.

80 L. Z. Zhao, J. J. Peng, Q. Huang, C. Y. Li, M. Chen, Y. Sun, Q. N. Lin, L. Y. Zhu and F. Y. Li, Adv. Funct. Mater., 2014, 24, 363-371.

81 Z. J. Chen, S. Q. He, H. J. Butt and S. Wu, Adv. Mater., 2015, 27, 2203-2206.
82 Z. Chen, W. Sun, H.-J. Butt and S. Wu, Chem. - Eur. J., 2015, 21, 9165-9170.

83 S. Q. He, K. Krippes, S. Ritz, Z. J. Chen, A. Best, H. J. Butt, V. Mailander and S. Wu, Chem. Commun., 2015, 51, 431-434.

84 E. Ruggiero, A. Habtemariam, L. Yate, J. C. Mareque-Rivas and L. Salassa, Chem. Commun., 2014, 50, 1715-1718.

85 Y. L. Dai, H. H. Xiao, J. H. Liu, Q. H. Yuan, P. A. Ma, D. M. Yang, C. X. Li, Z. Y. Cheng, Z. Y. Hou, P. P. Yang and J. Lin, J. Am. Chem. Soc., 2013, 135, 18920-18929.

86 Y. Z. Min, J. M. Li, F. Liu, E. K. L. Yeow and B. G. Xing, Angew. Chem., Int. Ed., 2014, 53, 1012-1016.

87 P. T. Burks, J. V. Garcia, R. GonzalezIrias, J. T. Tillman, M. T. Niu, A. A. Mikhailovsky, J. P. Zhang, F. Zhang and P. C. Ford, J. Am. Chem. Soc., 2013, 135, 18145-18152.

88 A. E. Pierri, P. J. Huang, J. V. Garcia, J. G. Stanfill, M. Chui, G. Wu, N. Zheng and P. C. Ford, Chem. Commun., 2015, 51, 2072-2075.

89 L. L. Fedoryshin, A. J. Tavares, E. Petryayeva, S. Doughan and U. J. Krull, ACS Appl. Mater. Interfaces, 2014, 6, 13600-13606.

90 W. Li, J. S. Wang, J. S. Ren and X. G. Qu, J. Am. Chem. Soc., 2014, 136, 2248-2251.

91 Z. J. Chen, Y. B. Xiong, R. Etchenique and S. Wu, Chem. Commun., 2016, 52, 13959-13962.

92 P. Lederhose, Z. J. Chen, R. Muller, J. P. Blinco, S. Wu and C. Barner-Kowollik, Angew. Chem., Int. Ed., 2016, 55, 12195-12199.

93 J. P. Lai, Y. X. Zhang, N. Pasquale and K. B. Lee, Angew. Chem., Int. Ed., 2014, 53, 14419-14423.

94 B. Zheng, L. Su, H. Pan, B. Hou, Y. Zhang, F. Zhou, X. Wu, X. Gong, H. Wang and J. Chang, Adv. Mater., 2016, 28, 707-714.

95 Z. W. Chen, L. Zhou, W. Bing, Z. J. Zhang, Z. H. Li, J. S. Ren and X. G. Qu, J. Am. Chem. Soc., 2014, 136, 7498-7504.

96 H. Maeda, M. Okada, S. Fujii, Y. Nakamura and T. Furuzono, Langmuir, 2010, 26, 13727-13731.

97 S. Fujii, M. Okada, T. Nishimura, H. Maeda, T. Sugimoto, H. Hamasaki, T. Furuzono and Y. Nakamura, J. Colloid Interface Sci., 2012, 374, 1-8.

98 C. Yao, P. Wang, X. Li, X. Hu, J. Hou, L. Wang and F. Zhang, Adv. Mater., 2016, 28, 9341-9348.

99 T. Sadhukha, T. S. Wiedmann and J. Panyam, Biomaterials, 2014, 35, 7860-7869.

100 S. Rose, A. Prevoteau, P. Elziere, D. Hourdet, A. Marcellan and L. Leibler, Nature, 2014, 505, 382-385.

101 H. Tran, K. L. Killops and L. M. Campos, Soft Matter, 2013, 9, 6578-6586.

102 J. Hodak, Z. J. Chen, S. Wu and R. Etchenique, Anal. Chem., 2016, 88, 1468-1475.

103 A. M. Kloxin, A. M. Kasko, C. N. Salinas and K. S. Anseth, Science, 2009, 324, 59-63.

104 J. C. Boyer and F. C. van Veggel, Nanoscale, 2010, 2, 1417-1419.

105 American National Standard for safe use of lasers, Laser Institute of America, Orlando, FL, 2000.

106 Laser safety handbook, Northwestern University, 2011. 
107 Y. F. Wang, G. Y. Liu, L. D. Sun, J. W. Xiao, J. C. Zhou and C. H. Yan, ACS Nano, 2013, 7, 7200-7206.

108 X. J. Xie, N. Y. Gao, R. R. Deng, Q. Sun, Q. H. Xu and X. G. Liu, J. Am. Chem. Soc., 2013, 135, 12608-12611.

109 Y. T. Zhong, G. Tian, Z. J. Gu, Y. J. Yang, L. Gu, Y. L. Zhao, Y. Ma and J. N. Yao, Adv. Mater., 2014, 26, 2831-2837.

110 J. Shen, G. Y. Chen, A. M. Vu, W. Fan, O. S. Bilsel, C. C. Chang and G. Han, Adv. Opt. Mater., 2013, 1, 644-650.

111 H. L. Wen, H. Zhu, X. Chen, T. F. Hung, B. L. Wang, G. Y. Zhu, S. F. Yu and F. Wang, Angew. Chem., Int. Ed., 2013, 52, 13419-13423.

112 Z. Hou, K. Deng, C. Li, X. Deng, H. Lian, Z. Cheng, D. Jin and J. Lin, Biomaterials, 2016, 101, 32-46.

113 S. Y. Han, R. R. Deng, X. J. Xie and X. G. Liu, Angew. Chem., Int. Ed., 2014, 53, 11702-11715.

114 W. Feng, L. D. Sun and C. H. Yan, Chem. Commun., 2009, 4393-4395.

115 N. J. Greybush, M. Saboktakin, X. C. Ye, C. Della Giovampaola, S. J. Oh, N. E. Berry, N. Engheta, C. B. Murray and C. R. Kagan, ACS Nano, 2014, 8, 9482-9491.
116 N. Mauser, D. Piatkowski, T. Mancabelli, M. Nyk, S. Mackowski and A. Hartschuh, ACS Nano, 2015, 9, 3617-3626.

117 N. Liu, W. Qin, G. Qin, T. Jiang and D. Zhao, Chem. Commun., 2011, 47, 7671-7673.

118 Z. Yin, Y. Zhu, W. Xu, J. Wang, S. Xu, B. Dong, L. Xu, S. Zhang and H. Song, Chem. Commun., 2013, 49, 3781-3783.

119 J. H. Lin, H. Y. Liou, C. D. Wang, C. Y. Tseng, C. T. Lee, C. C. Ting, H. C. Kan and C. C. Hsu, ACS Photonics, 2015, 2, 530-536.

120 L. Liang, Y. Liu, C. Bu, K. Guo, W. Sun, N. Huang, T. Peng, B. Sebo, M. Pan, W. Liu, S. Guo and X.-Z. Zhao, Adv. Mater., 2013, 25, 2174-2180.

121 Y. Li, G. Wang, K. Pan, B. Jiang, C. Tian, W. Zhou and H. Fu, J. Mater. Chem., 2012, 22, 20381-20386.

122 C. Yuan, G. Chen, P. N. Prasad, T. Y. Ohulchanskyy, Z. Ning, H. Tian, L. Sun and H. Agren, J. Mater. Chem., 2012, 22, 16709-16713.

123 M. Zhang, Y. Lin, T. J. Mullen, W.-f. Lin, L.-D. Sun, C.-H. Yan, T. E. Patten, D. Wang and G.-y. Liu, J. Phys. Chem. Lett., 2012, 3, 3188-3192. 